\title{
Comparative efficacy of captopril and allylmercaptocaptopril in the maintenance of oxidative-antioxidative equilibrium and attenuation of selenite-induced cataract in rats
}

\author{
K. S. LAKSHMI ${ }^{1}$ and Shrinivas SHARMA ${ }^{2^{*}}$ \\ ${ }^{I}$ Department of Pharmaceutical Analysis, SRM College of Pharmacy, SRM University Kattankulathur- \\ 603203. Tamilnadu, India. \\ ${ }^{2}$ Department of Pharmacology, SRM College of Pharmacy, SRM University, Kattankulathur- 603203. \\ Tamilnadu, India. \\ *Corresponding author, E-mail: shrinivas.sharma29@gmail.com, Tel.: +919381446030
}

\begin{abstract}
The present study was undertaken to investigate the comparative efficacy of captopril (CP) and allylmercaptocaptopril (AMC) supplementation following selenite exposure with respect to oxidant-antioxidant equilibrium and prevents cataract formation in rat pups. Forty Wistar-albino rat pups were equally divided into 4 groups. In Group I; only subcutaneous (s.c) saline was injected. In Group II; single dose of sodium selenite (19 $\mu \mathrm{M} / \mathrm{kg}$ body weight, s.c) was injected on postpartum day 10 . One day before the selenite challenge, the pups in Group III and IV were injected intraperitoneally a single dose of $50 \mathrm{mg} / \mathrm{kg}$ of CP and AMC respectively and repeated once daily thereafter up to $21^{\text {st }}$ day. The development of cataract was assessed weekly. The density of cataract was graded by slit-lamp biomicroscopy. On day 21 , the blood was collected and lenses were removed. Total oxidant status (TOS), total antioxidant capacity (TAC), oxidative stress index (OSI) and malondialdehyde (MDA) level were determined in the lenses of the rat pups. Serum paraoxonase-1 (PON1) activity was determined. All of the lenses of rat pups in Group I remained clean. All rat pups developed dense nuclear opacity in Group II. Three out of 10 rat pups developed slight nuclear opacity in Group III while only one rat pup out of 10 in Group IV had vacuolization but not opacity. Differences among the groups were statistically significant $(\mathrm{p}<0.01)$. Group II lenses had higher mean OSI and MDA level than those of Group III and IV ( $<<0.01)$. Group II lenses had lower mean TAC level and serum PON1 activity than those of Group III and IV ( $<<0.01)$. A negative correlation was found between serum PON1 activity and lens MDA level $(\mathrm{r}=-0.6861 ; \mathrm{P}<0.001)$. CP and AMC both diminished the incidence of cataract due to its protection of the antioxidant defense system but AMC was found to be more effective than CP.

(C) 2010 International Formulae Group. All rights reserved.
\end{abstract}

Keywords: Paraoxonase-1, oxidative stress index, malondialdehyde, total antioxidant capacity, total oxidant status, sodium selenite.

\section{INTRODUCTION}

Cataract is a major health problem and the major cause of blindness throughout the world (Taylor, 1993). Currently, the only available treatment for the disease is the surgical extraction of the cataractous lens followed by replacement with a synthetic implant. Although such a surgical replacement 
of the natural lens with an artificial lens is significantly effective in restoring vision to most patients, it is not free of complications. Attempts to prevent cataract formation, or at least significantly retard the onset of the disease would be of great value (Cornish et al., 2002).

Free radical-induced oxidative stress is postulated to be perhaps the major factor leading to senile cataract formation (Taylor and Hobbs, 2002). Oxidative stress originates due to an imbalance between the generations of reactive oxygen species (ROS) and their removal. Abnormally high levels of free radicals due to an over production/inadequate removal and simultaneous decline in antioxidant defense mechanism can damage cellular proteins, nucleic acids and membrane lipids (Berlett and Stadtman, 1997). Reactive oxygen species also initiate lipid peroxidation of polyunsaturated fatty acids (PUFAs) resulting in the production of reactive carbonyl compounds, among which malondialdehyde (MDA) is most abundant.

Owing to the involvement of free radicals, extensive studies have been conducted to identify oxidative stress biomarkers. Common biomarkers include antioxidant enzymes such as superoxide dismutase, glutathione peroxidase, glutathione reductase, and catalase. A decrease in activities of these enzymes in both blood and lens samples in subjects suffering from cataract has been reported (Donma et al., 2002; Ozmen et al., 2002; Ates et al., 2004; Hashim et al., 2006). Paraoxonase-1 (PON1) is an enzyme with paraoxonase, aryl esterase, and diazoxonase activities (Canales and Sanchez-Muniz, 2003). PON-1 protects LDL and HDL from oxidation induced by copper ions and free radical generators (Aviram et al., 1998). PON1 hydrolyzing activity of some activated phospholipids (Watson et al., 1995) and lipid peroxide products is associated with protection (Aviram et al., 1998). Furthermore, antioxidants preserve serum PON1 level
(Aviram et al., 1999). PON1 catalyzes the breakdown of organophosphates (Jakubowski, 2000; Josse et al., 2001) and also hydrolyzes homocysteine thio-lactone, which can harm some proteins by homocysteinylation. Reduced PON1 activities have been reported in cardiovascular diseases (McElveen et al., 1986; Navab et al., 1997), diabetes mellitus (Abbott et al., 1995; Mackness et al., 1998; Sakai et al., 1998), chronic renal failure (Dantoine et al., 1998), rheumatoid arthritis (Baskol et al., 2005), hyperthyroidism (Raiszadeh et al., 2004), age-related macular degeneration (Baskol et al., 2006) and in cataract (Hashim and Zarina, 2007).

Therefore, it can be postulated that the prevention of reactive oxygen production or scavenging of free radicals would be an effective strategy to prevent or delay cataract formation or progression. This strategy, in particular through the use of nutritional antioxidants, has received much attention from researchers (Meyer and Sekundo, 2005; Chiu and Taylor, 2007). Physiologic antioxidants such as isoflavone genistein and nutritional antioxidants such as ascorbate, vitamin $\mathrm{E}$, and carotenoids were found to delay the development of experimental cataract (Devamanoharan et al., 1999; Doganey et al., 2006; Huang et al., 2007).

In our previous studies, we have extensively evaluated the anticataract activity captopril (Lakshmi et al., 2009) and allylmercaptocaptopril (under publication) against selenite induced cataract in experimental animals. Allicin can covalently react with captopril to form allylmercaptocaptopril, in which the allyl moiety is linked via a disulfide bond to captopril (Miron et al., 2004; Oron-Herman et al., 2005).

To evaluate the comparative efficacy of captopril and allylmercaptocaptopril, we studied the correlation between lens MDA level and serum paraoxonase activity and assessed their protective effect in the 
maintenance of oxidative-antioxidative equilibrium in the lens and sera of seleniteinduced experimental cataract in rat pups.

\section{MATERIALS AND METHODS}

Chemicals

Captopril was kindly provided by Wockhardt Ltd (Aurangabad, Maharashtra, India) approximate purity was $98 \%$. Sodium selenite, diallyl disulfide and chemicals required for enzyme assay were purchased from Sigma Chemical Company, St. Louis, MO. All other chemicals and AR grade solvents were procured from SRL, Mumbai, India.

\section{Synthesis of allylmercaptocaptopril}

Allylmercaptocaptopril

was

synthesized by previous reported methods (Miron et al., 2004), with some major modifications. First, Allicin (diallyl disulfide oxide, Figure 1) was synthesized by a modified method of Stoll and Seebeck, (1948). Allylmercaptocaptopril (AMC) was synthesized by the addition of captopril (CP) solution (1 mmol in $7.5 \mathrm{ml}$ water, $\mathrm{pH} 5.5)$ to an aqueous solution of $0.55 \mathrm{mmol}$ allicin. The reaction was monitored by HPLC analysis until captopril was no longer detected. The reaction mixture was then acidified by hydrochloric acid and extracted by ether to remove non-reacted allicin. The water phase was extracted with ethyl acetate. The organic phase was dried by $\mathrm{Na}_{2} \mathrm{SO}_{4}$, filtered and evaporated, re-dissolved in ethanol, and dried by speed vacuum concentrator. The reaction product was analyzed by HPLC and its structure confirmed by IR, NMR and mass spectrometry. The reaction between captopril and allicin to form AMC is illustrated in Figure 1. The required amount of lyophilized AMC was dissolved in $1 \mathrm{ml}$ ethanol and diluted in water to attain the appropriate volume and kept in dark bottles. Fresh solutions were prepared daily for administration to animals.

\section{Anticataract activity}

Forty Wistar-albino rat pups were equally divided into four groups. Rats used for the study were obtained from the animal house stock of the Department of Pharmacology, SRM College of Pharmacy, Kattankulathur, India and handle in accordance with the guidelines as per the "Institutional Animal Ethical Committee" and CPCSEA (Committee for the Purpose of Control and Supervision of Experiments on Animals) rules. The rat pups were housed with their mothers. Each group contained ten rat pups. The rat pups in Group I, sham, received only subcutaneous (s.c.) saline. In Group II, sodium selenite $(19 \mu \mathrm{M} / \mathrm{kg}$ body weight, s.c) was injected on postpartum day 10. One day before the selenite challenge, the pups in Group III and IV were injected intraperitoneally a single dose of $50 \mathrm{mg} / \mathrm{kg}$ of $\mathrm{CP}$ and AMC respectively and repeated once daily thereafter up to $21^{\text {st }}$ day.

The pups were observed each day starting from the day their eyes opened (when the pups were 15 days old). The development of cataract was assessed daily by slit-lamp biomicroscope (TOPCON, Japan). One person (A.K), who was blinded to the group, performed biomicroscopic examinations of the lenses. On postpartum day 21 , adequate mydriasis was achieved by using a topical ophthalmic solution containing tropicamide with phenylephrine (Maxdil Plus, Hi-Care Pharma, Chennai, India) and the development of cataract was assessed; a) Mature dense opacity involving the entire lens; b) Slight nuclear opacity; and c) Normal clear lens.

\section{Biochemical measurements}

At the end of the trial, the rat pups were sacrificed and their encapsulated lenses were removed by posterior approach without any delay. The lenses were rinsed with physiological saline, blotted on filter paper, half of the lenses in each group were homogenized in pairs in 10 volumes of 
phosphate buffer (20 mM, pH 7.4) for the estimation of total oxidant status and total antioxidant capacity and remaining half of the lenses of all the groups homogenized in pair in $1 \mathrm{ml}$ of $0.15 \mathrm{M}$ potassium chloride for the estimation of MDA level. The supernatant was obtained by centrifugation in glass tubes at $6000 \mathrm{rpm}$ for 30 minutes and was used for measurements. For the measurement of serum PON1 activity, blood samples obtained from the inferior vena cava of the rat pups were placed into plain tubes. Blood in the plain tubes was allowed to clot for 20 minutes at room temperature followed by centrifugation at $3000 \mathrm{rpm}$ for 15 minutes and serum was separated and stored at $-80{ }^{\circ} \mathrm{C}$ until analysis.

\section{Total oxidant status (TOS)}

Total oxidant status (TOS) of lens was determined using a novel automated measurement method as previously described (Erel, 2005). Oxidants present in the sample oxidized the ferrous ion-o-dianisidine complex to ferric ion. The oxidation reaction was enhanced by glycerol molecules abundantly present in the reaction medium. The ferric ion produced a colored complex with xylenol orange in an acidic medium. The color intensity, which could be measured spectrophotometrically, was related to the total amount of oxidant molecules present in the sample. The assay was calibrated with hydrogen peroxide and the results were expressed in terms of micromolar hydrogen peroxide equivalent per liter $\left(\mu \mathrm{mol} \mathrm{H}_{2} \mathrm{O}_{2}\right.$ equivalent/L).

\section{Total antioxidant capacity (TAC)}

The total antioxidant status of the lens was measured using previously developed novel automated colorimetric measurement method (Erel, 2004). In this method, the hydroxyl radical, the most potent biological radical, is produced by the Fenton reaction, and reacts with the colourless substrate $\mathrm{O}$ dianisidine to produce the dianisyl radical, which is bright yellowish-brown in colour. Upon the addition of a lens homogenate, the oxidative reactions initiated by the hydroxyl radicals present in the reaction mixture are suppressed by the antioxidant components of the lens, preventing the colour change and thereby providing an effective measure of the total antioxidant capacity. The assay results are expressed as mmol Trolox eq./L, and the precision of this assay is excellent, being lower than $3 \%$.

\section{Oxidative stress index (OSI)}

The per cent ratio of the TOS of lens to the TAC of lens gave the OSI of the lens, an indicator of the degree of oxidative stress ((TOS / TAC) x 100) (Kosecik et al., 2005).

\section{Malondialdehyde (MDA)}

The extent of lipid peroxidation was determined by previously described method (Ohkawa et al., 1979). Briefly, $0.2 \mathrm{ml}$ of $8.1 \%$ sodium dodecyl sulphate, $1.5 \mathrm{ml}$ of $20 \%$ acetic acid $(\mathrm{pH} 3.5)$ and $1.5 \mathrm{ml}$ of $0.81 \%$ thiobarbituric acid aqueous solution was added in succession. To this reaction mixture, $0.2 \mathrm{ml}$ of lens homogenate (prepared in 0.15 M Potassium chloride) was added. The mixture was then heated in boiling water for $60 \mathrm{~min}$. After cooling to room temperature, 5 $\mathrm{ml}$ of butanol:pyridine $(15: 1 \mathrm{v} / \mathrm{v})$ solution was added. The mixture was then centrifuged at $5000 \mathrm{rpm}$ for $15 \mathrm{~min}$. The upper organic layer was separated, and the intensity of the resulting pink colour was read at $532 \mathrm{~nm}$. The level of lipid peroxide was expressed as $\mu \mathrm{mol}$ MDA/g wet weight for lens, using extinction coefficient $1.56 \times 10^{5} \mathrm{M}^{-1} \mathrm{~cm}^{-1}$.

\section{Paraoxonase-1 (PON1) activity}

PON1 activity toward paraoxon was determined by measuring the initial rate of substrate hydrolysis to $p$-nitrophenol, whose absorbance was monitored at $412 \mathrm{~nm}$ in the assay mixture $(800 \mu \mathrm{l})$ containing $2.0 \mathrm{mM}$ paraoxon, $2.0 \mathrm{mM} \mathrm{CaCl} 2$ and $20 \mu \mathrm{l}$ of serum 
in $100 \mathrm{mM}$ Tris- $\mathrm{HCl}$ buffer (pH 8.0). The blank sample containing incubation mixture without serum was run simultaneously to correct for spontaneous substrate breakdown. The enzyme activity was calculated from $E$ 412 of $p$-nitrophenol $(18,290 \mathrm{M}-1 \mathrm{~cm}-1)$ and was expressed in U/L serum; $1 \mathrm{U}$ of enzyme hydrolyses $1 \mathrm{nmol}$ of paraoxon per min (Gan et al., 1991).

\section{Statistical analysis}

All data were expressed as mean \pm SD. One-way ANOVA with post-hoc Dunnett's test were applied on the data showing normal distribution. Additionally, the Kruskal-Wallis test was used for the data showing abnormal distribution. Categorical variables were compared using the chi-squared test. Correlations between variables were calculated by Pearson's correlation coefficient (r). $\quad \mathrm{P}<0.05$ was considered statistically significant.

\section{RESULTS}

All of the lenses of rat pups in Group I remained clean. All rat pups developed dense nuclear opacity in Group II. Three out of 10 rat pups developed slight nuclear opacity in Group III. The other 7 rat pups in Group III had clear lenses. This difference was statistically significant $\left(\mathrm{x}^{2}(\mathrm{df}=1)=10.76\right.$; $\mathrm{P}<0.01)$. While, only one out of 10 rat pups showed slight vacuolization but not opacity in group IV. The other 9 rat pups in Group IV had clear lenses. This difference was also statistically significant $\left(\mathrm{x}^{2}(\mathrm{df}=1)=16.36\right.$; $\mathrm{P}<0.01)$.

As shown in Table 1 , the mean OSI level in Group II was significantly higher than the mean OSI levels in Group I, Group III and Group IV $(\mathrm{P}<0.01)$. The mean TOS level in Group II was significantly higher than those in Group I, Group III $(\mathrm{P}<0.05)$ and Group IV $(\mathrm{P}<0.01)$. The mean TAC level in Group II was significantly lower than those in Group I, Group III and Group IV $(\mathrm{P}<0.01)$.

A significant increase in MDA level was found in Group II opposed to the Group I animals $\quad(\mathrm{P}<0.01) . \quad \mathrm{CP}$ and $\mathrm{AMC}$ supplementation significantly protected $(\mathrm{P}<0.01)$ Group III and Group IV animals from lipid peroxidation which was found to be lowered in both groups.

In contrast, the mean serum PON1 activity in Group II was significantly lower than the mean serum PON1 activity in Group I, Group III and Group IV $(\mathrm{P}<0.001$; Figure 2). Because of the abnormal distribution in the data of PON1, non-parametric KruskalWallis test was employed for the analysis. There was a negative correlation between lens MDA levels and serum PON1 activity ( $\mathrm{r}=$ $0.6861 ; \mathrm{P}<0.001$; Figure 3).

Table 1: Levels of TOS, TAC, OSI and MDA in Group I, Group II, Group III and Group IV lenses.

\begin{tabular}{lcccc}
\hline Parameter & Group I & Group II & Group III & Group IV \\
\hline TOS & $14.19 \pm 3.16^{*}$ & $21.21 \pm 3.11$ & $17.14 \pm 3.21^{\#}$ & $13.19 \pm 2.04 *$ \\
$\left(\mu \mathrm{M} \mathrm{H} \mathrm{O}_{2}\right.$ eq/L) TAC & $4.70 \pm 0.50 *$ & $1.36 \pm 0.33$ & $3.17 \pm 0.41 *$ & $4.46 \pm 0.32 *$ \\
$(\mathrm{mM} \mathrm{Trolox} \mathrm{eq/L)} \mathrm{SI(AU)}$ & $3.10 \pm 0.92 *$ & $9.81 \pm 1.19$ & $5.08 \pm 0.87 *$ & $3.77 \pm 0.88^{*}$ \\
$\mathrm{MDA}(\mu \mathrm{mol} / \mathrm{g})$ & $0.045 \pm 0.001 *$ & $1.147 \pm 0.02$ & $0.078 \pm 0.001 *$ & $0.058 \pm 0.001 *$ \\
\hline
\end{tabular}

All values are expressed as mean \pm SD. Group I: Normal, Group II: rat pups treated with selenite only. Group III: rat pups treated with selenite and CP, Group IV: animals treated with selenite and AMC. Statistically significant difference ( ${ }^{\#} \mathrm{P}<0.05$, ${ }^{*} \mathrm{P}<0.01$ ) when compared with group II values. TOS: Total oxidant status, TAC: Total antioxidant capacity, OSI: Oxidative stress index, MDA: Malondialdehyde. 


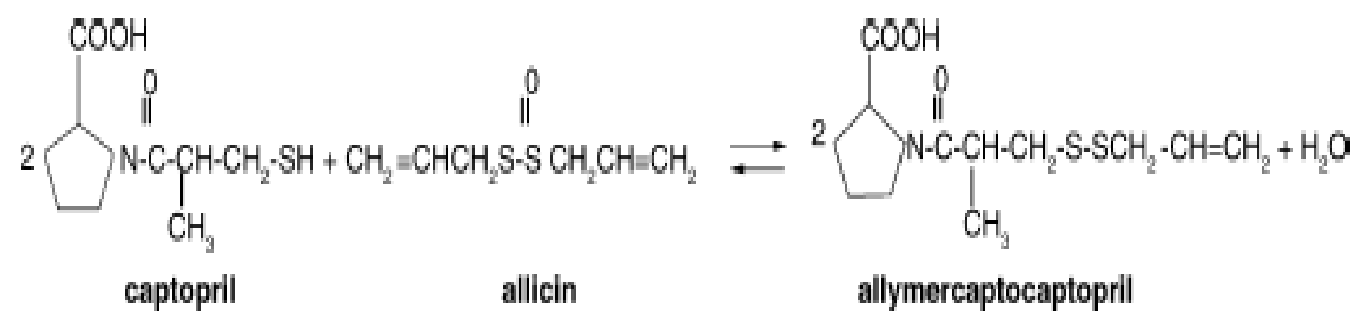

Figure 1: Schematic illustration of the chemical reaction between captopril and allicin that forms allylmercaptocaptopril.

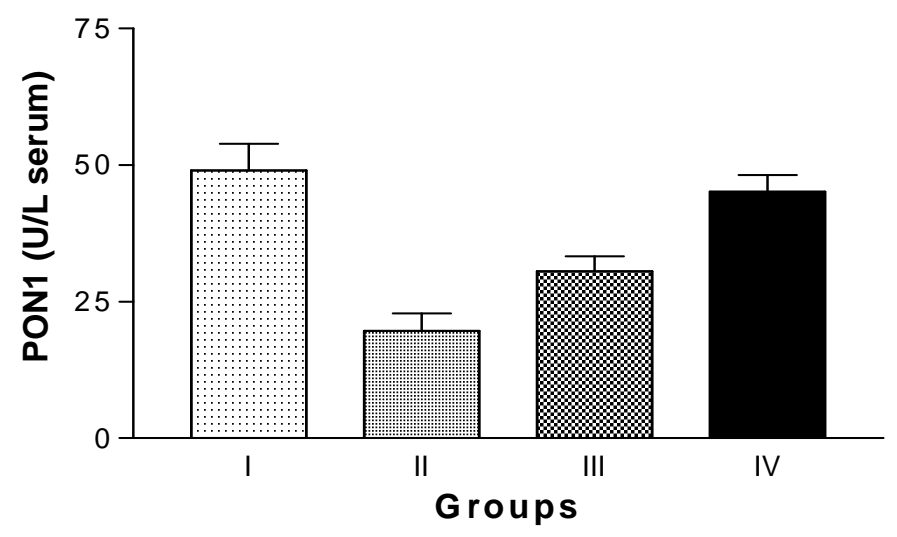

Figure 2: Serum PON1 activity. All values are expressed as mean \pm SD. Group I: Normal, Group II: selenite treated, Group III: selenite and CP treated, Group IV: selenite and AMC treated. PON1: Paraoxanase 1.

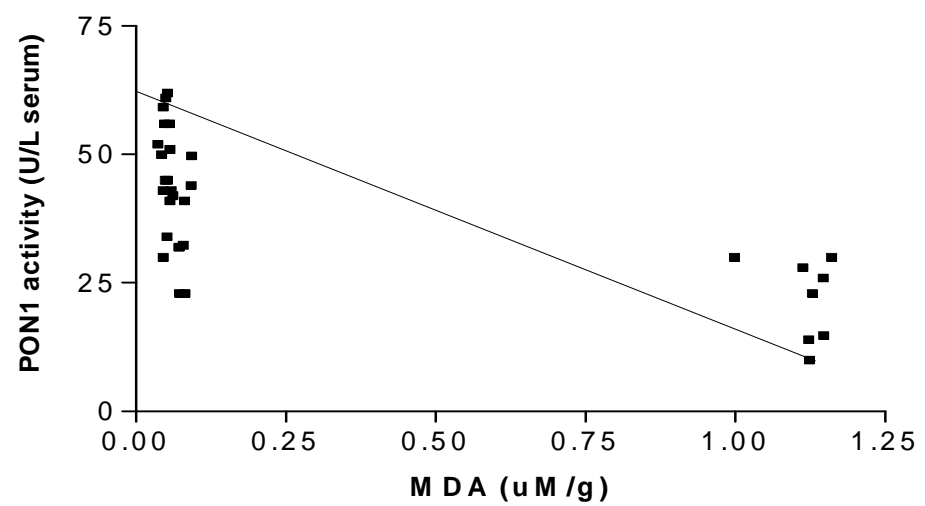

Figure 3: Correlation between lens MDA levels and paraoxonase activity in selenite and drugs treated animals. 


\section{DISCUSSION}

Oxidative stress is implicated in the etiology of many diseases including Alzheimer, Parkinsonism, diabetes and cataract (Halliwel, 2001; Truscott, 2005; Vinson, 2006). During oxidative stress, high reactive molecules such as superoxide radicals, hydrogen peroxides and hydroxyl radicals are produced. These molecules, if present in excess, can damage DNA, cellular proteins and lipids (Berlett and Stadtman, 1997). The rate of generation of reactive oxygen species (ROS) roughly correlates with life span and during aging, oxidant/antioxidant balance is disturbed in favour of the former (Kregel and Zhang, 2007). Selenite-induced cataract formation is a convenient, rapid, and reproducible experimental cataract model (Ostadalova et al., 1978). The role of oxidative stress in selenite-induced cataract formation has been previously reported (Shearer et al., 1997). Selenite causes oxidation of cell components, including the proteins, and forms a covalent linkage with protein sulfhydryl. An augmentation of the antioxidant defenses of the lens has been shown to prevent or delay cataract (Spector et al., 1995). Based on our previous findings on captopril as anticataractogenic agent (Lakshmi et al., 2009), we predicted that allylmercaptocaptopril, a covalent conjugate of allicin with the ACE inhibitor captopril, would have a greater impact and therapeutic efficacy in correcting oxidative stress induced cataract in animals than captopril alone. Various biomarkers have been studied to examine the level of oxidative stress in lens as well as blood samples from cataract subjects.

Paraoxonase is another antioxidant enzyme which is a calcium-dependent esterase that is widely distributed among tissues such as liver, kidney, intestine and plasma ( $\mathrm{La} \mathrm{Du}$, 1996; Mackness et al., 1996). In mammals, three genes, PON1, PON2 and PON3, have been identified among which, only PON1 has been studied extensively because PON2 is absent from human serum (Ng et al., 2001) and PON3 is present in very low amount. PON1 is closely associated with high-density lipoproteins (HDL) (Berliner et al., 1995; La Du, 1996; Mackness et al., 1996) and acts as an antioxidants enzyme since it protects oxidation of low-density lipoprotein (LDL) from oxidative damage both in vivo and in vitro (Aviram et al., 1999). PON1 catalyzes the breakdown of organophosphates (Jakubowski, 2000; Josse et al., 2001) and also hydrolyzes homocysteine thio-lactone, which can harm some proteins by homocysteinylation. Reduced PON1 activities have been reported in cataract subjects.

In the present study, we found that the mean serum PON1 activity in selenite-treated rats was significantly lower than the mean PON1 levels in the CP and AMC treated rats $(\mathrm{p}<0.01)$. The lower mean PON1 level in selenite treated rat was due to oxidative stress of selenite. We observed that CP and AMC restored the serum PON1 level but the effect was more pronounced in AMC treated group.

PON1 activity is known to be inhibited by lipid peroxidation (Aviram et al., 1999). To examine the status of lipid peroxidation, we estimated lens MDA (product of membrane lipid peroxidation) concentration in all groups. Our data indicated highest degree of lipid peroxidation in selenite treated cataractous animals as compared to $\mathrm{CP}$ and AMC treated group of animals. MDA concentration was significantly restored in CP and AMC treated group comparable to normal. Our results are consistent with earlier studies which report higher MDA levels in plasma and lens samples from cataract subjects (Orhan et al., 1999). Babizhavev et al. (2004) have shown that the injection of lipid peroxidation products into the vitreous humour can induce cataract formation.

We observed a negative correlation between MDA levels and paraoxonase activity $(\mathrm{r}=-0.6861)$. Interestingly, the magnitude and 
association between low PON1 activity and high lipid peroxides in cataract formation are consistent with worse oxidant balance and it was found to be reversed when treated with $\mathrm{C}$ and AMC which proved its antioxidant efficacy.

Reactive oxygen species (ROS) are produced in metabolic and physiological processes, and harmful oxidative reactions may occur in organisms which remove them via enzymatic and nonenzymatic antioxidative mechanisms. In cataract, the increase in oxidants and decrease in antioxidants cannot be prevented, and the oxidative/antioxidative balance shifts towards the oxidative status. To evaluate the oxidative stress index, we measured lens total oxidant status and total antioxidant capacity. TOS was found to be significantly higher in selenite treated group while TAS was decreased due to the oxidative stress provoking effect of selenite as compared to normal. Treatment of $\mathrm{CP}$ and AMC was found to be effective as they increased the lens total antioxidant capacity and decreased total oxidant status. These findings are in agreement that both drugs are capable to maintain oxidative-antioxidative equilibrium in lens. But the effect was more pronounced in AMC treated group.

Our study supports the hypothesis that lipid peroxidation plays a crucial role in inactivation of PON1. The observed decline in serum PON1 activity among selenite treated group of animals appears to be mainly a consequence of oxidative stress. Our results clearly indicate that oxidative imbalance is more pronounced in case of cataractous subjects. A direct cause-and effect relationship, however, may not be so straightforward since oxidative stress appears to generate multifactorial response. The approaches that target reduction in rate of ROS generation and/or induction of antioxidant activities may prove beneficial. Captopril and AMC, found to be beneficial to restore the oxidative imbalance in cataractous subjects, may be useful for prophylaxis or therapy against cataracts.

\section{ACKNOWLEDGEMENTS}

Authors are grateful to Prof. Dr. R. Sivakumar, Pro-Vice Chanceller, SRM University and Prof. Dr. K. Ilango, Vice Principal, SRM College of Pharmacy, SRM University, Kattankulathur for providing financial support and necessary facilities respectively to carryout this work. Authors express their profound gratitude to Dr. S. P. Sharma (Ophthalmologist) for providing slitlamp biomicroscope and technical support during the entire study.

\section{REFERENCES}

Abbott CA, Mackness MI, Kumar S, Boulton AJ, Durrington PN. 1995. Serum paraoxonase activity, concentration and phenotype distribution in diabetes mellitus and its relationship to serum lipids and lipoproteins. Arterioscler. Thromb. Vasc. Biol., 15: 1812 - 1818.

Ates NA, Yildirim O, Tamer L, Unlu A, Ercan B, Muslu N, Kanik A, Hatungil R, Atik U. 2004. Plasma catalase activity and malondialdehyde level in patients with cataract. Eye., 18: 785 - 788.

Aviram M, Rosenblat M, Bisgaier CL, Newton RS, Primo-Parmo SL, La Du BN. 1998. Paraoxonase inhibits high-density lipoprotein oxidation and preserves its functions: a possible preoxidative role for paraoxonase. J. Clin. Invest., 101: 15811590.

Aviram M, Rosenblatt M, Billecke S. 1999. Human serum paraoxonase (PON1) is inactivated by oxidized low density lipoprotein and preserved by antioxidants. Free. Radic. Biol. Med., 26: 892 - 904.

Babizhayev MA, Deyev AI, Yermakova VN, Brikman IV, Bours J. 2004. Lipid peroxidation and cataracts: $\mathrm{N}$ acetylcarnosine as a therapeutic tool to manage age-related cataracts in human 
and in canine eyes. Drugs. R. D., 5: $125-$ 139.

Baskol G, Demir H, Baskol M, Kilic E, Ates F, Kocer D, Muhtaroglu S. 2005. Assessment of paraoxonase 1 activity and malondialdehyde levels in patients with rheumatoid arthritis. Clin. Biochem., 38: $951-955$.

Baskol G, Karakucuk S, Oner AO, Baskol M, Kocer D, Mirza E, Saraymen R, Ustdal M. 2006. Serum paraoxonase 1 activity and lipid peroxidation levels in patients with age-related macular degeneration. Ophthalmologica., 220: $12-16$.

Berlett BS, Stadtman ER. 1997. Protein oxidation in aging, disease, and oxidative stress. J. Biol. Chem., 272: 20313-20316.

Berliner JA, Navab M, Fogelman AM, Frank JS, Demer LL, Edwards PA, Watson AD, Lusis AJ. 1995. Atherosclerosis: basic mechanisms. Oxidation, inflammation, and genetics. Circulation., 91: 2488 2496.

Canales A, Sanchez-Muniz FJ. 2003. Paraoxonase, something more than an enzyme? Med. Clin. (Barc)., 121: 537 548.

Chiu CJ, Taylor A. 2007. Nutritional antioxidants and age-related cataract and maculopathy. Exp. Eye. Res., 84: 229 245.

Cornish KM, Williamson G, Sanderson J. 2002. Quercetin metabolism in the lens: Role in inhibition of hydrogen peroxide induced cataract. Free. Radic. Biol. Med., 33: 63-70.

Dantoine TF, Debord J, Charmes JP, Merle L, Marquet P, Lachatre G, Leroux-Robert C. 1998. Decrease of serum paraoxonase activity in chronic renal failure. J. Am. Soc. Nephrol., 9: 2082 - 2088.

Devamanoharan PS, Henein M, Ali AH. 1999. Attenuation of sugar cataract by ethyl pyruvate. Mol. Cell. Biochem., 200: 103 109.
Doganay S, Borazan M, Iraz M, Cigremis Y. 2006. The effect of resveratrol in experimental cataract model formed by sodium selenite. Curr Eye Res., 31: 147 153.

Donma O, Yorulmaz E, Pekel H, Suyugul N. 2002. Blood and lens lipid peroxidation and antioxidant status in normal individuals, senile and diabetic cataractous patients. Curr. Eye. Res., 25: $9-16$.

Erel O. 2005. A new automated colorimetric method for measuring total oxidant status. Clin. Biochem., 38: 1103 - 1111.

Erel O. 2004. A new automated method to measure total antioxidant response against potent free radical reactions. Clin. Biochem., 37: 112 - 119.

Gan KN, Smolen A, Eckerson HW, La Du BN. 1991. Purification of human serum paraoxonase/arylesterase. Drug. Metab. Dispos., 19: 100 - 106.

Halliwel B. 2001. Role of free radicals in the neurodegenerative diseases: therapeutic implications for antioxidant treatment. Drugs. Aging., 18: 685 - 716.

Hashim Z, Zarina S. 2006. Antioxidant markers in human senile and diabetic cataractous lenses. J. Coll. Physicians. Surg. Pak., 16: 637 - 640.

Hashim Z, Zarina S. 2007. Assessment of paraoxonase activity and lipid peroxidation levels in diabetic and senile subjects suffering from cataract. Clin. Biochem., 40: 705 - 709.

Huang R, Shi F, Lei T, Song Y, Hughes CL, Liu G. 2007. Effect of the isoflavone genistein against galactose-induced cataracts in rats. Exp Biol Med., 232: 118-125.

Jakubowski H. 2000. Calcium-dependent human serum homocysteine thiolactone hydrolase: a protective mechanism against protein $\mathrm{N}$-homocysteinylation. $J$. Biol. Chem., 275: 3957 - 3962. 
Josse D, Lockridge O, Xie W, Bartels CF, Schopfer LM, Masson P. 2001. The active site of human paraoxonase (PON1). J. Appl. Toxicol., 21: S7 - S11.

Kosecik M, Erel O, Sevinc E, Selek S. 2005. Increased oxidative stress in children exposed to passive smoking. Int. J. Cardiol., 100(1): $61-64$.

Kregel KC, Zhang HJ. 2007. An integrated view of oxidative stress in aging: basic mechanisms, functional effects and pathological considerations. Am. J. Physiol. Regul. Integr. Comp. Physiol., 292: R18 - 36.

La Du BN. 1996. Structural and function diversity of paraoxonases. Nat. Med., 2: $1186-1187$.

Lakshmi KS, Sharma S, Rajesh T. 2009. Captopril ameliorates sodium selenite induced cataractogenesis in rats: An in vitro and in vivo study. Pharmacologyonline, 2: 1205 - 1215.

Mackness B, Mackness MI, Arrol S, Turkie W, Julier K, Abuasha B, Miller JE, Boulton AJ, Durrington PN. 1998. Serum paraoxonase (PON1) 55 and 192 polymorphism and paraoxonase activity and concentration in non-insulin dependent diabetes mellitus. Atherosclerosis., 139: 341 - 349.

Mackness MI, Mackness B, Durrington PN, Connelly PW, Hegele RA. 1996. Paraoxonase: biochemistry, genetics and relationship to plasma lipoproteins. Curr. Opin. Lipidol., 7: 69 - 76.

McElveen J, Mackness MI, Colley CM, Peard T, Warner S, Walker CH. 1986. Distribution of paraoxon hydrolytic activity in the serum of patients after myocardial infarction. Clin. Chem., 32: $671-673$.

Meyer CH, Sekundo W. 2005. Nutritional supplementation to prevent cataract formation. Dev. Ophthalmol., 38: 103 119.
Miron T, Rabinkov A, Peleg E. 2004. Allylmercaptocaptopril: a new antihypertensive drug. Am. J. Hypertens., 17: 71-73.

Ng CJ, Wadleigh DJ, Gangopadhay A, Hama S, Grijalva V, Navab M, Fogelman AM, Reddy ST. 2001. Paraoxonase-2 is a ubiquitously expressed protein with antioxidant properties and is capable of preventing cell-mediated oxidative modification of low density lipoprotein. J. Biol. Chem., 276: 44444 - 44449.

Navab M, Hama-Levy S, Van-Lenten BJ, Fonarow GC, Cardinez CJ, Castellani LW, Brennan ML, Lusis AJ, Fogelman AM, La Du BN. 1997. Mildly oxidized LDL induces an increased apolipoprotein J/paraoxonase ratio. J. Clin. Invest., 99: 2005 - 2019.

Ohkawa H, Ohishi N, Yagi K. 1979. Assay of lipid peroxide in animal tissue by thiobarbituric acid reaction. Anal. Biochem., 95: 351 - 358.

Orhan H, Marol S, Hepsen IF, Sahin G. 1999. Effects of some probable antioxidants on selenite induced cataract formation and oxidative stress related parameters in rats. Toxicol., 139: 219 - 232.

Oron-Herman M, Rosenthal T, Mirelman D. 2005. The effects of Sallylmercaptocaptopril, the synthetic product of allicin and captopril, on cardiovascular risk factors associated with the metabolic syndrome. Atherosclerosis., 183: $238-243$.

Ostadalova I, Babicky A, Obenberger J. 1978. Cataract induced by administration of a single dose of sodium selenite to suckling rats. Experientia., 34: $222-223$.

Ozmen B, Ozmen D, Erkin E, Guner I, Habif S, Bayindir O. 2002. Lens superoxide dismutase and catalase activities in diabetic cataract. Clin. Biochem., 35: $69-$ 82.

Raiszadeh F, Solati M, Etemadi A, Azizi F. 2004. Serum paraoxonase activity before 
and after treatment of thyrotoxicosis. Clin. Endocrinol., 60: 75 - 80.

Sakai T, Matsuura B, Onji M. 1998. Serum paraoxonase activity and genotype distribution in Japanese patients with diabetes mellitus. Intern. Med., 37: 581 584.

Shearer TR, Ma H, Fukiage C, Azuma M. 1997. Selenite nuclear cataract: review of the model. Mol. Vis., 3: 8 .

Spector A. 1995. Oxidative stress induced cataract: mechanism of action. FASEB. J., 9: $1173-1182$.

Stoll A, Seebeck E. 1948. Die Synthese des naturlichen Alliins und seiner drei optisch aktiven Isomerasen. Hel. Chim. Acta., 31: $189-210$.

Taylor A. 1993. Cataract: Relationship between nutrition and oxidation. J. Am. Coll. Nutr., 12: 138 - 146.
Taylor A, Hobbs M. 2002. The 2001 assessment of nutritional influences on risk of cataract. Nestle. Nutr. Workshop. Ser. Clin. Perform. Programme., 6: 163 189.

Truscott RJ. 2005. Age-related nuclear cataract - oxidation is the key. Exp. Eye. Res., 80: $709-725$.

Vinson JA. 2006. Oxidative stress in cataracts. Pathophysiol., 13: $151-162$.

Watson AD, Berliner JA, Hama SY. 1995. Ptotective effect of high density lipoprotein associated paraoxonase. Inhibition of the biological activity of minimally oxidized low density lipoprotein. J. Clin. Invest., 96: 2882 2891. 